Brit. J. industr. Med., 1958, 15, 273.

\title{
SOME NOTES ON THE EFFECTS OF EXCESSIVE NOISE ON THE HEARING OF A GROUP OF WORKERS*
}

BY

\author{
G. F. KEATINGE and S. LANER
}

From the Medical Department, the Butterley Company Limited, Ripley, Derby, and the Operational Research Department, the British Iron and Steel Research Association, London

(RECEIVED FOR PUBLICATION AUGUST 3, 1957)

The data for the present investigation were collected between August, 1951, and August, 1956, in the Butterley Company's works at Codnor Park. In some of the shops of these works the noise is so intense that outsiders experience it as unpleasant and in some spots even as unbearable. During the period mentioned no protective devices were in use, largely because the workers found many of the existing protectors both uncomfortable and otherwise inconvenient.

The availability of audiometric records of workers who had been exposed to noise for periods from one year to seven years made possible a first attempt to relate deterioration in hearing to prolonged exposure to intense intermittent noise. That such deterioration (based on permanent and irreversible changes in the auditory organs) occurs is well known. But the relationship between length of exposure and loss is somewhat complicated by the fact that a certain amount of loss is brought about by the natural process of ageing (presbycusis).

\section{Measurement of Noise}

To assess the overall level of ambient noise in the three shops where it appeared to reach maximum intensity, measurements were taken by means of the Dawe sound level meter, Type 1400D. The maximum readings are shown in Table 1. Samples of the noise measured were simultaneously recorded on tape for subsequent frequency analysis.

Shop No. 3 is a large building, of which the walls are partly of brick and partly of corrugated iron; the roof is of asbestos. The reverberation effects in the shop are considerable. Most of the workers on the shop floor are engaged more or less directly in the riveting of wagon undercarriages, the operatives most immediately exposed to noise being the riveter himself and the holder-up who

* Read before a joint meeting of the Ergonomics Research Society and the British Occupational Hygiene Society, held in London on June 28, 1957.
TABLE 1

MAXIMUM READINGS OF NOISE IN THREE SHOPS

\begin{tabular}{|c|c|c|}
\hline Site & Placing of Meter & $\begin{array}{c}\text { Maximum } \\
\text { Reading } \\
\text { (in Decibels) }\end{array}$ \\
\hline $\begin{array}{l}\text { Shop No. } 3 \\
\text { Shop No. } 7 \\
\text { Shop No. } 7 \\
\text { Shop No. } 1\end{array}$ & $\begin{array}{l}\text { Beside riveter } \\
\text { Outside aluminium trough } \\
\text { Inside aluminium trough } \\
\text { Beside riveter }\end{array}$ & $\begin{array}{l}115 \\
122 \\
128 \\
116\end{array}$ \\
\hline
\end{tabular}

maintains the steel rivets in place. The sound meter here, and for all other measurements, was placed at a distance from the noise source approximating to the usual distance of the operative from it.

In Shop No. 7 large aluminium troughs, used ultimately as superstructures for pit trams or trolleys, are riveted. The noise was measured both outside the trough, i.e., at the position taken up by the riveter, and inside it, where the holder-up keeps the rivet in place.

Shop No. 1 is similar to Shop No. 3 in layout and in the operations carried out. A spot check taken at a distance of 10 yards from the noise source in a bay of Shop No. 1 gave a reading of $102 \mathrm{db}$.

Table 2 shows the frequencies at which the noises measured reached their peak intensities.

TABLE 2

PEAK INTENSITIES OF MEASURED NOISE

\begin{tabular}{|c|c|}
\hline Site & $\begin{array}{l}\text { Peak Intensity } \\
\text { (c./sec.) }\end{array}$ \\
\hline 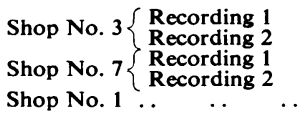 & $\begin{array}{l}1,500-2,000 \\
1,500-2,000 \\
1,000-1,500 \\
1,500-2,000 \\
1,500-2,000\end{array}$ \\
\hline
\end{tabular}

The noises recorded all reached their peak intensities at frequencies at which with prolonged exposure they are likely to produce damage attended by loss of hearing.

\section{Hearing Tests}

The assessment of the hearing of the workers was carried out by pure tone audiometry and the loss of hearing at the frequencies of $128,256,512,1,024,4,096$, and 8,192 cycles per second was recorded by the method 
MAME. AGE. No.

ADDRESS._ DATE.

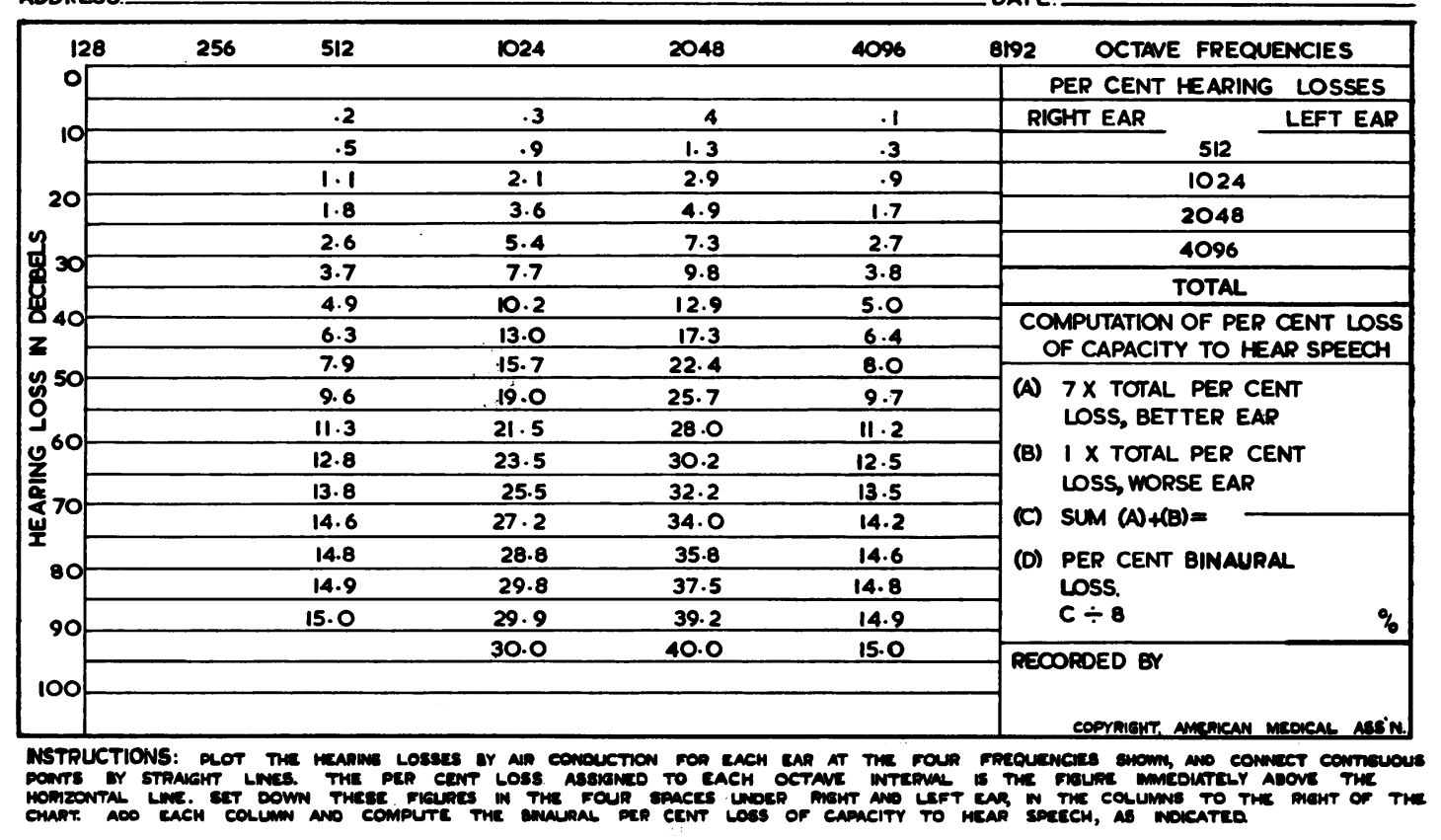

FiG. 1

described by Fowler (1947), in which the decibel grading of the audiogram is supplemented by percentage ratings of loss of hearing o t the sounds of normal speech, which are principally in the band 512-4,096 cycles per second. Since the sounds falling into the narrower band of 1,024 to 2,048 cycles per second are the most important for interpreting speech and losses in these frequencies are thus more serious, they are given higher loss percentage ratings. The special chart (Fig. 1) makes it possible to obtain an average loss percentage rating for hearing speech for both ears (binaural loss).

The tests were undertaken in a quiet room in the works surgery which is situated approximately 50 yards from the nearest workshop. Admittedly there was some background noise, but all the tests were carried out by the same tester under the same conditions and can thus reasonably be compared with each other. None of the workers suffered from chronic ear disease in any form. All had the ears examined before testing and if cerumen was found, it was removed, and the hearing tested two days later.

\section{Exposure Period and Hearing Loss}

Two straightforward measures were taken to control factors which might otherwise have vitiated the results of the attempt to relate length of exposure to noise with loss of capacity to hear speech.
To eliminate the complicating factor of hearing loss due to ageing, the rate of which increases steeply after the age of 40 , the audiograms of all workers of and above this age were excluded from the analysis.

Secondly, audiograms were obtained for a control group of 20 subjects, consisting of new starters and others who had never been exposed to intense noise for any appreciable length of time. The audiometric procedure was carried out in the same room by the same tester who had tested the experimental subjects. The obvious purpose of having a control group was to provide a base line: the loss percentages obtained for members of the control group cannot be ascribed to exposure to intense noise and are probably due in the main to ambient noise in the test chamber.

Table 3 gives the mean percentage of binaural loss of hearing of speech for each exposure group. The second column $(\mathrm{N})$ shows the number of audiograms on which the mean value is based.

Inspection of the third column in Table 3 suggests at first that hearing loss is a direct function of the exposure period, but this consistent trend is broken by the group with the longest exposure period.

Statistical treatment showed that increases (or 
TABLE 3

MEAN PERCENTAGE LOSS OF HEARING OF SPEECH FOR EACH GROUP

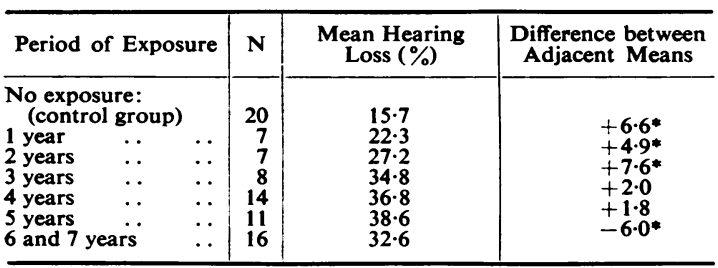

decreases) in hearing loss as large as or larger than those marked by an asterisk, could occur by chance only five times in a hundred. This means that, in so far as the results obtained are representative of the position in general, during the first three years impairment in the capacity to hear speech proceeds at an appreciable rate, possibly reflecting a concomitant rate of damage to the auditory apparatus. The decrease in the rate of impairment after three years' exposure, and the reversal in impairment for the six and seven years' exposure group suggests that exposure for three years caused so much damage that a ceiling was reached; to test this hypothesis a much larger volume of data would be needed.

The practical implications of this analysis are that anti-noise protective devices may have their maximum effectiveness if introduced to people at the start of their employment on noisy jobs: that they can still be of considerable effectiveness if introduced during the first, second, and third years of exposure; and that the value of using them after three years of uninterrupted free exposure to intense noise has either gone or is in doubt.

\section{Effect of Age}

As individuals with longer exposure are, as a rule, also older, the possibility that greater hearing loss in each successive exposure group might have been due at least in part to the higher age of its members was examined. Apart from the gross obtrusion of presbycusis which was eliminated by excluding the records of those aged 40 and over, it seemed wise to scrutinize the remaining records for any consistent trend indicating hearing loss due to ageing rather than to exposure.

The available data made it possible to calculate the regression of hearing loss on age, or, in other words, to " measure" the magnitude of any trend due to ageing. This trend is expressed in the test
TABLE 4

SUMMARY OF REGRESSION ANALYSIS

\begin{tabular}{l|c|c|c}
\hline \multicolumn{1}{c|}{ Source of Variation } & $\begin{array}{c}\text { Degrees } \\
\text { of } \\
\text { Freedom }\end{array}$ & $\begin{array}{c}\text { Mean } \\
\text { Squares }\end{array}$ & $\begin{array}{c}\text { Test } \\
\text { Ratio }\end{array}$ \\
\hline $\begin{array}{l}\text { Regression of hearing loss on age } \\
\text { Residual variation }\end{array}$ & 81 & $\begin{array}{r}21.9 \\
207.7\end{array}$ & 0.11 \\
\hline
\end{tabular}

ratio in the summary of the regression analysis in Table 4.

It can be shown that a trend as high as or higher than that measured by the above test ratio would be expected to occur by chance with a probability of 0.4. This means that no consistent effect of age differences on hearing loss was apparent in our data.

\section{Summary}

Measurements at three shops of the Butterley Company, Codnor Park Works, suggested that the ambient noise might reach levels deleterious to hearing. Frequency analysis showed that the noise reached its peak in the band critical for speech perception.

Analysis of the audiometric records of workers under 40 years of age exposed to this noise continuously for periods from one to seven years suggested that the initial exposure period of up to three years is attended by the greatest hearing loss.

After the first three years' exposure the rate of deterioration appeared to slow down or possibly even to cease.

It is suggested that protective devices may be optimally effective if introduced at entry into the job or soon afterwards.

More data are needed to test the hypothesis that after three years' exposure no further deterioration occurs, the damage previously sustained having possibly reached a ceiling.

The authors are indebted to the workers at the Butterley Company Limited for their ready cooperation when measurements were taken. Thanks are also due to $\mathrm{Mr}$. W. G. R. Hore, surgeon in the Ear, Nose, and Throat Department of the Derbyshire Group of Hospitals, for advice and help in the technique of audiometry and in the interpretation of audiograms: and to Mrs. E. R. Buxton, nursing sister in charge of the surgery at the Codnor Park Group of Works of the Butterley Company Limited, for much help in the organization and in the carrying out of these tests.

\section{REFERENCE}

Fowler, E. P. (1947). Laryngoscope (St. Louis), 57, 103. 